\title{
La web y la emergencia \\ de una nueva estructura de conocimientos*
}

\author{
Ollivier Dyens ${ }^{* *}$ \\ Traducción del francés al español \\ de Luis Alfonso Palau Castaño \\ DOI: $10.22395 /$ csye.v5n10a13
}

\begin{abstract}
[...] Psychologists and sociologists already are beginning to note a change taking place in cognitive development among youngsters in the so-called "dot-com" generation. [...] Others see the development in a more positive light, as a freeing up of the human consciousness to be more playful, flexible, and even transient in order to accommodate the fast-moving and ever changing realities people experience. Today's children, they argue, are growing up in a world of networks and connectivity in which combative notions of mine and thine, so characteristic of a propertied market economy, are giving way to a more interdependent and embedded means of perceiving reality-one more cooperative than competitive and more wedded to systems thinking and consensus building (Rifkin, pp. 12-13).
\end{abstract}

Soy muy afortunado. Comencé a enseñar de tiempo completo en la universidad relativamente muy joven. Tenía apenas treinta años. A pesar de eso, como muchos profesores mayores con los que compartía mi tarea, percibía a mis estudiantes como peligrosamente sub-educados. Impotentes para concentrarse, dedicados a lo superficial y a lo aleatorio, sin conocimientos históricos y enciclopédicos, incapaces de escribir bien; los estudiantes que frecuentaban mis clases me parecían mal preparados para afrontar los desafíos y problemas de una sociedad que no paraba de hacerse más compleja. Y, sin embargo, mientras que numerosos profesores y yo mismo hacíamos este diagnóstico, las tecnologías operaban una transformación radical de la estructura de la economía, acompañada del crecimiento más importante en la historia de Occidente. Nuestras economías se desmaterializaban, intercambiando átomos más bien que octetos (así como lo subrayaba Nicholas Negroponte ${ }^{1}$ ), acumulando pasajes

Tomado de: Ollivier Dyens. Le web et l'emergence d'une nouvelle structure de connaissances. 2002. HAL Id: sic 00000267 https://archivesic.ccsd.cnrs.fr/sic 00000267 (on line: https://halshs.archives-ouvertes. fr/sic_00000267/document). Traducción del francés al español de Luis Alfonso Palau Castaño, Medellín, agosto 27 de 2016.

** Département d'Études françaises. Université Concordia. 2002

1 (Nicholas Negroponte, informático y arquitecto estadounidense de origen griego, más conocido como fundador y director del MIT Media Lab, un laboratorio de diseño y nuevos medios del Instituto Tecnológico de Massachusetts. Wikipedia). 
y chorreos más bien que objetos, intercambiando estilos de vida en vez de materias (así como lo analizaba Naomi Klein ${ }^{2}$ ) y esto, gracias a una industria, la de la informática, creada por completo por esos estudiantes que habían frecuentado nuestras instituciones. Actualmente, la economía contemporánea es del trueque memético (de memes), del crecimiento cognitivo, del producto intelectual interno bruto. En menos de diez años, esos jóvenes hombres y mujeres cuya formación intelectual me parecía profundamente inadecuada, han logrado trastocar las fundaciones económicas e intelectuales de Occidente.

¿Cómo fue esto posible? ¿Cómo esos jóvenes que criticábamos tanto, que parecían poseer tan mal esas herramientas cognitivas que nosotros creíamos esenciales para el desarrollo intelectual, podían ser los actores principales de una transformación tan importante?

Desde hacía ya muchos años, una nueva estructura de adquisición de conocimientos había hecho su aparición. Una estructura que los jóvenes utilizaban para comprender el mundo, de la que se servían para darle color y textura, con la que navegaban por los mares agitados de las complejidades contemporáneas, una estructura que éramos (y somos aún) incapaces de identificar, de legitimar y de explotar. Una nueva estructura de adquisición de los conocimientos que está hoy infiltrada en casi todos los dominios de la investigación, del conocimiento y de la cultura.

Pero ¿cuál es esa estructura?

\section{Es la de la aceleración y la superficialidad}

Como lo dice Pierre Levy, el tiempo hoy es esencialmente una nueva velocidad de aprendizaje colectivo (p. 23). ¿Por qué? Porque se trata de un tiempo nuevo, ya no orgánico sino maquínico y tecnológico. Como nos lo han probado las investigaciones sobre la relatividad, el tiempo no es absoluto sino que existe por la intermediación de contactos que nosotros tenemos con objetos y fenómenos que pueblan nuestras vidas (tales como los ciclos del corazón, por ejemplo, o los de la naturaleza). Esos contactos son hoy esencialmente maquínicos y reticulares, y por esto, la aceleración de nuestra percepción del tiempo (las máquinas y redes, al aumentar regularmente su velocidad de ejecución, nos arrastran por sus contactos, a una estructura temporal cada vez más rápida). Habitamos ahora un mundo mucho más rápido y afiebrado como para que no podamos comprenderlo con nuestras herramientas cognitivas clásicas. De hecho, por las tecnologías, la relación que tenemos con el tiempo es en la actualidad tan acelerada que ya no es humanamente posible administrar la información que de ella emana

\begin{tabular}{ll}
\hline 2 & (Periodista, escritora, investigadora canadiense, reconocida en los medios antiglobalización y del socialismo \\
democrático, autora de No Logo, Vallas y ventanas, la Doctrina del shock y Esto lo cambia todo. Google».
\end{tabular} 
de manera lineal y vertical; la toma, el análisis, la gestión y la conservación de datos que emanan de muchas fuentes, desplegándose en muchas direcciones, multiplicándose en innumerables dimensiones a la vez (por esto la ausencia de memoria colectiva que de ello resulta, al no expresarse la memoria, sino a través del filtrado y el olvido. Cuando nada se olvida, nada adquiere, entonces, valor de rememoración).

Pero la nueva estructura de adquisición de los conocimientos, dado que se despliega de forma horizontal, porque ella busca percibir y comprender los movimientos (y no sus causas), porque se nutre de percepciones globales, porque sondea el deslizamiento más bien que la profundización, es capaz de administrar lo efímero, lo evanescente y lo inestable temporal. Pero para que ello ocurra, la nueva estructura de adquisición de los conocimientos utiliza la superficialidad.

¿Se trata de una transformación negativa de la adquisición de conocimientos? No, pues el término "superficial" debe actualmente ser comprendido de manera diferente. El medievalista Alexandre Leupin habla de homonimización. ¿En qué consiste? El trastrueque tan profundo de una estructura de pensamiento por la aparición de un nuevo concepto, que los términos que lo preceden y lo siguen, aunque idénticos en apariencia, ven cómo se modifica su definición respectiva. Antes y después de Galileo, por ejemplo, la palabra "cosmos" designa un universo completamente diferente. Antes y después de Cristo, la palabra "dios" adquiere una significación completamente distinta. Antes y después de la aceleración del tiempo tal y como la vivimos hoy, la palabra "superficial" cambia también de definición.

Frente a las tensiones (sociales, físicas e informacionales) cada vez más numerosas de nuestro entorno, la superficialidad ya no es signo de pereza, sino claramente de inteligencia, pues la velocidad con la que debemos absorber y reaccionar a la información es muchísimo más importante, como para que nos pongamos a utilizar estrategias cognitivas más antiguas como son la reflexión, la contemplación y el análisis sistemático.

Pero regresemos algunos instantes al concepto de homonimización tal como lo desarrolla Alexandre Leupin ${ }^{3}$. Según este investigador, la homonimización solo es posible si un acontecimiento contundente echa por tierra, por su impacto, al pensamiento dominante. ¿Cuál es este evento que nos fuerza hoy a ver con otros ojos y a redefinir la palabra "superficial"?

\footnotetext{
3 (Alexandre Leupin, suizo nacido en Ginebra, es Gregorie Professor in French at Louisiana State University, Baton Rouge, donde enseña French literature, arte, epistemología y psicoanálisis. Ha publicado Le Graal et la litterature, Barbarolexis, Fiction and Incarnation, La Passion des idoles, \& Phallophanies otherpress.com Paláus.
} 
Yo veo tres: la aceleración del tiempo (tal como se ha explicado precedentemente), la aparición de la Web en 1994 (con Mosaic) y la emergencia de CNN y de MTV en los años 80.

\section{La Web}

La Web propone una concepción y una percepción del mundo cuya esencia no es simplemente arborescente o la hipertextualidad, sino claramente el volumen. Para captar la Web, el internauta debe navegar, pasearse, explorar. Para comprender la Web, el internauta no puede estar inmóvil. La Web no es una biblioteca, no es un receptáculo pasivo de informaciones. La Web es un lugar, una tierra, un continente. Para vivir y ser eficaz en ella, hay que saltar de un lugar y de un acontecimiento a otro, desplazarse, surfear sobre la continua expansión de esa red y atrapar en ella, aquí y allá, briznas de información. En la Web es imposible (y diría incluso peligroso) tratar de profundizar. La Web es moviente, y frente a dicha movención, el internauta no puede permanecer inmóvil. Esta necesidad de movimiento tiene un impacto profundo sobre la utilización de la superficialidad y sobre el desarrollo de la nueva estructura de adquisición de los conocimientos, puesto que ella obliga a deslizarse, puesto que empuja al éxodo, puesto que hace del nomadismo la estructura primera de la adquisición de los conocimientos.

Me permito un paréntesis aquí para explorar un poco este punto. El nomadismo intelectual que la Web impone no empobrece sino que enriquece. Como lo subrayan Pierre Levy ${ }^{4}$ y Hebert Simon ${ }^{5}$ y Philip Yam ${ }^{6}$, la riqueza de un entorno

4 «Il existe une relation directe entre l'interconnexion d'un organisme (ou son degré de sensibilité à lui-même) et la richesse du monde qu'il expérimente. Nous supposons, sans trop de risque de nous tromper, que le monde propre d'un oiseau, par exemple, brille de plus de couleurs, résonne de plus de sons, étend plus d'espace que celui d'une huître. Or ni la couleur, ni le son, ni peut-être l'espace n'existent dans le " monde extérieur ". Ce sont des produits des calculs très complexes des systèmes nerveux évolués, des émergences à partir d'un certain degré d'interconnexion. Plus un être est interconnecté à l'intérieur, plus son champ d'interaction est vaste, plus son expérience est riche, mieux il est capable d'apprendre (c'est-à-dire d'agrandir son monde), plus il est connecté à l'extérieur.n (Lévy, p. 50).

5 «En The Sciences of the Artificial (1981), Simon describe el camino indirecto que toma una hormiga que camina por un terreno desigual y lleno de obstáculos. Las paradas, hesitaciones y desvíos de su progresión son causados por los obstáculos que ella encuentra. Simon concluye entonces que una hormiga, percibida en tanto que sistema de comportamientos es generalmente resultado de la complejidad de su entorno [...] Es interesante anotar que si aplicamos este concepto a los seres humanos, poseemos entonces un argumento de peso para proponer que la cultura es fundamental para la formación de la inteligencia. La inteligencia no crece en la obscuridad como lo hace un champiñón, sino que está más bien dependiente de las interacciones con un medio rico y variado. La cultura es pues tan fundamental para la creación de los seres humanos como estos últimos lo son para la creación de cultura. Antes que denigrar de nuestra inteligencia, esta idea subraya más bien la coherencia y la riqueza milagrosa de las culturas que han tomado forma a partir de la existencia de los seres humanos.» (Luger \& Stubblefield p. 12).

$6 \quad$ "Are we truly smarter than our grandparents? Researchers aren't sure just what has caused the rise. Genetics clearly cannot operate on such a short time scale. Ulric Neisser of Cornell University thinks it may have to do 
contribuye directamente al desarrollo cognitivo. Entre más rico sea un entorno en desafíos, en preguntas, en novedades, más se desarrolla y se hace complejo el cerebro. La Web, por la cantidad de sus estímulos visuales, sonoros y textuales, por la velocidad a la que ellos están constantemente renovándose (y remplazándose), por el movimiento y el nomadismo que les impone a los internautas, fuerza al cerebro a resolver innumerables nuevos desafíos informacionales.

\section{CNN \& MTV}

CNN \& MTV han participado también activamente en la reorganización de nuestra estructura cognitiva, y en la redefinición de la palabra "superficial". ¿Cómo? Proponiendo un género de alfabetismo extremo de la imagen. Por CNN \& MTV, la imagen que experimentamos es cada vez más rápida y su significación es cada vez más efímera. Solo la superficialidad puede captar esta imagen.

Pero la influencia de estas estaciones de televisión cableadas no se detiene ahí. CNN \& MTV, por la escalada visual e informacional que producen, obligan a sus telespectadores a una comprensión del mundo resumida, ya no simplemente en superficie, sino también temporalmente comprimida.

Pues ¿qué produce CNN? No una reflexión o un análisis de los acontecimientos mundiales sino más bien una lectura del mundo humano, siempre en presente, siempre en tiempo real, siempre anclada en lo inmediato (por lo demás, la palabra «live» es la que mejor define esa cadena de televisión). CNN es el instante presente. Siempre. CNN no existe en una progresión ni en una perspectiva temporales, sino simplemente en una "serie de presentes sucesivos" (tomando prestados los términos de la Yourcenar). CNN crea un mundo de lo inmediato al que es necesario responder inmediatamente.

En cuanto a MTV, aunque ese canal no esté anclado al presente (de hecho él opera mucho más como una suerte de eco del tiempo; los vídeo-clips existen por fuera de las consideraciones del directo, y dos de sus terceras partes de programación sólo son la repetición del otro tercio), no por ello deja de participar él también en la febrilidad informacional, en la sinopsis temporal y en la representación en superficie en la que está hundido nuestro mundo. MTV es un lugar de producción febril de imágenes sin profundidad. Las imágenes de MTV son gestos, poses, cambios, nada de danza, primeros planos que solo se despliegan en la horizontalidad. MTV no puede proponer profundidad, no puede reconocer la verticalidad.

with the increasing visual complexity of modern life. Images on television, billboards and computers have enriched the visual experience, making people more capable in handling the spatial aspects of the IQ tests" (Yam, p. 8). 
Aceleración del tiempo, emergencia de la Web, aparición de CNN \& de MTV; estos son los acontecimientos que han provocado el trastrueque del pensamiento y por los que la homonimización del término "superficial" es posible.

\section{La estructura neuronal}

La nueva estructura de adquisición de los conocimientos no es pues ni lineal, ni vertical. No se despliega por la mediación del conocimiento enciclopédico, del análisis o de la contemplación.

Hace un ratico proponía que la masa de información a la que debemos hacer frente es, en el caso de la Web, una "extensión" moviente y cambiante. ¿Qué quiere decir? Que un intrigante paralelo puede ser establecido entre estructuras informacionales de la Web y la estructura neuronal del cerebro. Tanto la una como la otra son volúmenes variables cuya complejidad no conocemos y cuya esencia no es la acumulación, sino más bien el camino. De hecho, tanto en el cerebro como en la Web, la información emerge del paso (de neurona en neurona, o de sitio en sitio) y se vuelve conocimiento por la creación de lazos entre esos pasajes.

Pero esto no es privativo de la Web. El conjunto de los mass-media opera con el mismo principio. Televisión, radio, multimedia, teléfonos celulares, juegos de vídeo, etc.; los media actuales son, también ellos, inmensos volúmenes de informaciones inestables (por esto la necesidad de la superficialidad) en los que el conocimiento es pasaje, chorreo, transición. Por esto nuestra era está marcada por el solapo, el mestizaje, la intertextualidad y la intermedialidad; al solo ser posible el conocimiento por la creación de enlaces (de contaminaciones); solo las afinidades infecciosas permiten nuevos entendimientos.

Por esto es que nos dejamos engatusar por los nuevos media, por esto consagramos una importante parte de nuestras vidas frotándonos en ellos; esos volúmenes nos invitan a explorarlos de la misma manera que exploramos nuestro pensamiento; a saltos, asociaciones, interconexiones y apartes. La nueva estructura de conocimientos nos seduce, pues ella reproduce dinámicas cognitivas atávicas; no analizar y contemplar, sino más bien ver, desplazarse, captar y reaccionar.

$$
* * *
$$

[...] Psychologist Robert J. Lifton calls this new generation "protean" human beings. [...] They live in a world of seven-second sound bites, are used to quick access to and retrieval of information, have short attention spans, and are less reflective and more spontaneous. [...] While they are less able to compose a written sentence, they are better able to process electronic data. They 
are less analytical and more emotive. [...] Their world are less boundaried and more fluid. They grew up with hypertext, Web site links, and feedback loops, and have a perception of reality that is more systemic and participatory than linear and objective. They are able to send e-mail to people's virtual addresses without ever having to know or even care about their geographic addresses. [...] They are continually remaking themselves as they try on new lifestyles with each new passage of life. [...] They are experimental and court innovation. Customs, conventions, and traditions, on the other hand, are virtually nonexistent in their fast-paced, ever changing environment (Rifkin, pp. 186-187).

¿Cuáles son las consecuencias de esta nueva estructura de adquisición de conocimientos? Son numerosas. La más importante, y ciertamente la más contundente, es la transformación profunda de nuestra relación con lo escrito.

Como lo dice Michael Gibbons ${ }^{7}$, las humanidades siempre se han definido por su enlace con el texto, pero esa conexión se ha fragilizado ahora por la presión que ejercen la velocidad, la superficialidad y la contaminación de las nuevas estructuras de adquisición de conocimientos.

¿Por qué? Porque el texto, en su forma clásica, es centrípeto: atrae al lector, lo aprisiona (por medio de la seducción) en sus palabras, sus frases y sus reflexiones. Lineal, el texto es autoritario y dominador. Exige concentración y focalización.

El texto es, a la vez, fuente de la experiencia y de la memoria humana, y espejo de la relación que el hombre tiene con el tiempo, a causa de su biología. El texto es centrípeto, pues su primer papel es mnemotécnico; debe recordarse, debe conservarse en la memoria, debe ser capaz de reproducir un suceso, una información, una emoción, cuando se sienta la necesidad. El texto es el recuerdo humano del placer, del dolor y del sufrimiento. El texto es lineal pues es el espejo de los ciclos humanos; en él se refleja la percepción que tenemos de nuestra existencia, dado que introducción, desarrollo y conclusión no son sino simples imágenes del ciclo nacimiento/vida/muerte.

Pero los volúmenes de información -puesto que sólo develan su entendimiento en el pasaje y la contaminación- son centrífugos (un más allá nos interpela aquí constantemente). Entonces, la narración se pierde; he ahí por qué se pierde la facultad de escribir lineal y analíticamente. El conocimiento actual se adquiere en el viaje; se desvela en la partida, se transforma en el éxodo. El texto clásico representa al hombre en su medio biológico. La nueva estructura de adquisición de conocimientos refleja al hombre en las metamorfosis continuas de sus universos electrónicos.

\footnotetext{
http://www.fceia.unr.edu.ar/geii/maestria/2013/ADOLFO\%20STUBRIN/BIBLIOGRAF\%C3\%8DA\%202013/ Lectura\%205.\%20Pertinencia\%20de\%20la\%20educacion\%20superior\%20en\%20el\%20siglo\%20XXI.pdf Paláu.
} 
¿Será que nos estamos hundiendo en un mundo menos inteligente y menos humano? Creo más bien que nos sumergimos en un mundo donde las bases de lo que fundaba nuestra cultura (la acumulación histórica, la contemplación, el análisis) se nos han escapado. Ahora somos libres. Libres para comprometernos (¿para atollarnos?) en la creatividad y en la transformación. Libres para inventarnos y reinventarnos sin cesar. Libres para vivir y alimentarnos con lo inacabado y lo aleatorio. Pero también condenados a la fragilidad y a lo efímero. Este es el resultado del último decenio; en esto ha consistido la magnífica explosión de las bolsas y de las economías y su caída dramática; el movimiento rápido, frágil, creativo, pero incierto, de la nueva estructura de adquisición de los conocimientos.

Como lo dice Jeremy Rifkin ${ }^{8}$ al comienzo de este ensayo, henos pues al pie de una nueva cultura que administra de manera eficaz lo aleatorio, lo incierto y lo pasajero; una cultura que comprende los movimientos y las corrientes, y para la que la estabilidad ya no es un objetivo por alcanzar sino simplemente un precario estado en el que el equilibrio es nutrido por el caos. Henos pues, dirían Kevin Kelly, Steven Johnson, Harold Bloom ${ }^{9}$, Derrick de Kerchkhove ${ }^{10}$ \& Pierre Lévy, henos al pie de una cultura que se parece a un conjunto moviente e inteligente, una estructura que reacciona con inteligencia a los desafíos de su entorno por medio de la circulación de sus individuos y por la información que ese movimiento no cesa de generar. Kelly ${ }^{11}$, Johnson ${ }^{12}$, Lévy hablarían de inteligencia colectiva, conectiva, de jauría y de enjambre, en suma: de una estructura de adquisición de conocimientos que escanea, que surfea, que maniobra en tiempo real y cuya esencia no es la acumulación, sino más bien la reacción. Esta es la cultura a la que debemos poner cara hoy, la cultura que guía y esculpe nuestro mundo. Esta es la estructura de adquisición de los conocimientos que no llegamos a identificar; esta es la dinámica cognitiva que no llegamos ni a legitimar ni a explotar.

8 ।Jeremy Rifkin es un sociólogo, economista, escritor, orador, asesor político y activista estadounidense. Rifkin investiga el impacto de los cambios científicos y tecnológicos en la economía, la fuerza de trabajo, la sociedad y el medio ambiente. Obras: El fin del trabajo (1995), La tercera revolución industrial. Wikipedia).

9 (Harold Bloom, teórico y crítico literario estadounidense. Autor de El canon de Occidente (1994) La escuela y los libros de todas las épocas. Barcelona: Anagrama, 2005; Shakespeare, la invención de lo humano (1999). Bogotá: Norma, 2001\%.

10 (Derrick de Kerckhove, sociólogo belga nacionalizado canadiense. Es el Director del Programa McLuhan en Cultura y Tecnología, autor de La piel de la Cultura y de la Inteligencia Conectada, Wikipedia).

11 (Kevin Kelly, estadounidense, es el fundador y director ejecutivo de la Revista Wired, y en el pasado fue editor y publicista del Whole Earth Catalog. También ha sido un escritor, fotógrafo, conservacionista, y estudiante de culturas asiáticas y de la cultura digital. Wikipedia).

12 (Steven Johnson es un escritor de divulgación científica norteamericano. Ha trabajado como columnista en gran cantidad de publicaciones, entre las que se destacan The New York Times, The Wall Street Journal... Wikipedia). 
Esta es la cultura que nutre a los muchachos que frecuentan nuestras universidades.

\section{Bibliografía}

Bloom, Howard: Global Brain: the Evolution of Mass Mind from the Big Bang to the 21st Century. John Wiley \& Sons, Inc., United States, 2000.

Chazal, Gerard. Formas, figuras, realidad. tr. Paláu, Medellín, noviembre 2011.

Chazal, Gérard. El espejo autómata, introducción a una filosofía de la informática. tr. Paláu, Medellín, junio de 2014.

Dagognet, François. Caras, superficies, interfaces [Faces, Surfaces, Interfaces], Paris, Vrin, 1982. tr. Paláu, Medellín, marzo de 2007.

Gibbons, Michael, Limoges, Camille, Nowotny, Helga et al: The New Production of Knowledge, Sage Publications, London, 1994.

Higuinen, Erwan, Tesson, Charles: "Cinéphiles et ludophiles ", Cahiers du cinéma, hors-série, spécial jeux vidéos, septembre 2002, p. 4.

Johnson, Steven. Emergence: the Connected Lives of Ants, Brains, Cities, and Software. Scribner, NewYork, 2001.

Kelly, Kevin: New Rules for the New Economy: 10 Radical Strategies for a Connected World, Penguin Books, 1999.

Kelly, Kevin: Out of Control. The New Biology of Machines, Social Systems and the Economic World, Addison-Wesley Publishing Company, Readings, Massachusetts, 1994.

Kerckhove, Derrick de: Connected Intelligence: The Arrival of the Web Society, Somerville House Books, 1997.

Klein, Naomi. No Logo: Taking Aim at the Brand Bullies. Vintage Canada Edition, Toronto, 2000.

Lévy, Pierre (1987). La máquina universo. Creación, cognición y cultura informática. Tr. Paláu, Medellín, Instituto Tecnológico Metropolitano. Grupo de Investigación "Devenires estéticos", abril-mayo de 2013.

Lévy, Pierre (2000). World Philophie, Paris, Éditions Odile Jacob.

Luger, George F, Stubblefield, William A. Artificial Intelligence, Structures and Strategies for complex Problem Solving, The Benjamin-Cummings Publishing Company, Inc.Redwood City, 1993.

Rifkin, Jeremy. The Age of Access. Jeremy P. Tarcher/Putnam, New York, 2000.

Serres, Michel Pulgarcita. https://www.google.com.co/?ion=1\&espv=2\#q=michel\%20 serres\%20pulgarcita\%20pdf

Yam, Philip (1998). «Intelligence Considered». Scientific American, Exploring Intelligence, Winter 1998, Volume 9, Number 4 pp. 6-11. 
